\title{
DISCRICIONARIEDADE, CONCEITO JURÍDICO INDETERMINADO E ACCOUNTABILITY NO CONTEXTO DOS INCENTIVOS FISCAIS ${ }^{1}$
}

\author{
DISCRICTIONARIETY, INDETERMINATED \\ LEGAL CONCEPT AND ACCOUNTABILITY IN \\ THE CONTEXT OF TAX INCENTIVES
}

LEONARDO BUISSA FREITAS ${ }^{2}$ MATEUS ROCHA DE LISBÔA ${ }^{3}$

\section{RESUMO}

A construção histórica do Estado brasileiro aponta para acentuado grau de desigualdade regional entre as unidades federativas. Em decorrência disso, diversos Estados membros passaram a adotar os incentivos fiscais de ICMS como mecanismo para fomento e desenvolvimento socioeconômico. Nesse contexto, emerge um problema de grande monta: o controle e a limitação dos incentivos tributários. Nesse contexto, o presente estudo buscou analisar a incidência da discricionariedade, do conceito jurídico indeterminado e do accountability nos incentivos de ICMS concedidos pelo Estado de Goiás. Para tanto, se utilizou o método hipotético-descritivo, recorrendo-se à revisão da literatura e a exposição crítica dos temas abordados. Dessa forma, compreendeu-se os aspectos centrais relativos à dualidade entre tipo e conceito, discricionariedade, conceito jurídico indeterminado e accountability, fundados nos referencias teóricos de Humberto Ávila, Maria Sylvia Di Pietro, Floriano de Azevedo Marques Neto e Luis Felipe Sampaio. Ademais, a análise dos programas Fomentar, Produzir e Pró Goiás também foi objeto central desta pesquisa, bem como a observação dos atuais conceitos administrativistas acima citados no contexto de tais programas de incentivo tributário. Dessa maneira, restou constatada que a discricionariedade dos incentivos em comento devem ser limitadas pela realização de criterioso e efetivo accountability.

PALAVRAS-CHAVES: Accountability. Conceito jurídico indeterminado. Discricionariedade. Incentivos fiscais.

1 Este artigo faz parte de pesquisa científica desenvolvida junto ao programa de pós-graduação de Direito e Políticas Públicas da Universidade Federal de Goiás

2 Doutor em Direito Econômico, Financeiro e Tributário/USP. Professor do PPGDP/UFG. Pesquisador no Projeto Finanças e Políticas Públicas: análises, planejamento e controle no contexto do Federalismo Fiscal cooperativo. Juiz Federal. E-mail: leonardobuissa@gmail.com.

3 Graduado em Direito pela Universidade Federal de Goiás; Mestrando em Direito e Políticas Públicas pela Universidade Federal de Goiás; Pós Graduando em Direito Tributário pela Universidade de São Paulo; advogado. ORCID iD: https://orcid. org/0000-0001-8759-9228. E-mail: mateusrochalisboa95@gmail.com. 


\section{ABSTRACT}

The historical construction of the Brazilian State points to a marked degree of regional inequality between the federal units. As a result, several member states have adopted the ICMS tax incentives as a mechanism for socio-economic development and development. In this context, a major problem emerges: the control and limitation of tax incentives. In this context, the present study sought to analyze the incidence of discretion, the indeterminate legal concept and accountability in the ICMS incentives granted by the State of Goiás. For that, the hypothetical-descriptive method was used, using the literature review and the critical exposure of the topics covered. Thus, the central aspects related to the duality between type and concept, discretion, undetermined legal concept and accountability were understood, founded on the theorical references of Humberto Ávila, Maria Sylvia Di Pietro, Floriano de Azevedo Marques Neto and Luis Felipe Sampaio. Furthermore, the analysis of the Fomentar, Produir and Pró Goiás programs was also central to this research, as well as the observation of the current administrative concepts mentioned above in the context of such tax incentive programs. Thus, it was found that the discretion of the incentives in question must be limited by the realization of judicious and effective accountability.

KEY WORDS: Accountability. Discretion. Undetermined legal concept. Tax incentives.

\section{CONSIDERAÇÓES INICIAIS}

A construção do Estado brasileiro se deu, historicamente, de maneira desigual e sem a elaboração e execução consistente de algum projeto que considerasse o território nacional como um todo, favorecendo, assim, ao surgimento de consideráveis disparidades regionais, de modo que, ao lado da existência de centros pujantes economicamente, existem regiões com índice de desenvolvimento socioeconômico em menor grau.

Diante dessa realidade, bem como frente à persistente ausência de políticas públicas efetivas e duradouras de âmbito nacional voltadas para o desenvolvimento das regiões com menores índices socioeconômicos, os Estados membros, constatados os entraves que possuem para o desenvolvimento em grau mais acentuado de seu território, passaram, ao longo do século XX, a adotar a instituição de programas de incentivo fiscal de ICMS para a atração de maiores investimentos do setor privado.

Em razão da relevância que tais programas de incentivo fiscal foram assumindo no decorrer das últimas décadas, em especial para os Estados situados nas regiões Centro-Norte do país, se tornou de primeira ordem de importância a investigação relativa a tal fenômeno, em especial em decorrência do considerável poder que tais incentivos conferem aos representantes políticos, tendo em vista que a renúncia fiscal deles advinda é de elevada monta.

Ciente da relevância que tais formas de fomento da economia apresentam para grande parte dos Estados brasileiro, esta pesquisa centrar-se-á na análise de conceitos atuais que envolvem o Direito Administrativo, em especial os de discricionariedade, conceito jurídico indeterminado e accountability, para que seja possível compreender a existência de eventuais falhas tipológicas por parte dos programas objeto deste estudo.

A análise dos incentivos fiscais sob o viés de tais conceitos fornecidos pela disciplina jus administrativista decorre do problema central que o presente estudo irá abordar: a malversação dos incentivos fiscais de ICMS. Em decorrência do peso que tais benefícios pos- 
suem, os governantes se veem imbuídos de considerável poder político em mãos para dispor, sendo necessário, portanto, efetivo controle sobre sua concessão e execução.

Tal controle, cabe desde já enfatizar, se torna prioritário justamente porque a deflagração da anomalias no tratamento dos incentivos fiscais é nefasta para o Estado membro que o instituiu, não apenas pelos efeitos às finanças públicas de cada unidade federada, como também pela ineficiência e inefetividade que deles pode advir, contribuindo para o agravamento das precárias condições socioeconômicas do Estado instituidor.

Assim, realizando um recorte epistemológico no Estado de Goiás, o presente artigo concentrar-se-á na análise dos principais incentivos fiscais-financeiro instituídos por essa unidade da Federação, no caso, os programas Fomentar, Produzir e Pró Goiás.

Dessa forma, constata-se que o Estado de Goiás, através de seus programas de fomento, será objeto desta pesquisa, delimitando-se a análise ora elaborada aos limites territoriais deste ente político. Ademais, pontua-se que o lapso temporal em estudo remonta ao ano de 1984 até os dias atuais, tendo em vista que o primeiro desses programas instituído, qual seja, o Fomentar, foi promulgado por lei estadual que data do referido ano da década de 1980.

Nesse sentido, diante do problema aqui exposto, qual seja, a possível malversação tipológica de programas de incentivo fiscal sob a ótica de elementos centrais do atual Direito Administrativo, obtém-se como objetivo geral desta pesquisa a compreensão de como deve e como se dá a incidência da discricionariedade, do uso de conceitos jurídicos indeterminados e de accountability nos diplomas legais instituidores de tais incentivos de fomento econômico, tendo em vista a importância central que tais benesses tributárias possuem nos dias atuais para a economia dos Estados membros que os instituem.

Para tanto, buscar-se-á, como objetivo específico primeiro, o entendimento dos três conceitos fundamentais trazidos ao bojo desta pesquisa: discricionariedade, conceito jurídico indeterminado e accountability. Além disso, a compreensão do instituto dos incentivos fiscais, a partir de uma análise conceitual e tipológica, se torna de suma relevância.

Em seguida, para que o estudo concreto dos programas objeto desta pesquisa se concretize, esta pesquisa apresenta como segundo objetivo específico a descrição e a compreensão das leis instituidoras dos programas Fomentar, Produzir e Pró Goiás.

Ainda, manifesta-se igualmente como objetivo específico desta pesquisa, a compreensão de como se deve processar a incidência dos três elementos jus administrativistas suscitados sob a ótica das referidas leis de regência desses programas de incentivo fiscal concedidos pelo Estado de Goiás.

Assim sendo, a metodologia utilizada para se alcançar o resultado pretendido, qual seja, a análise da discricionariedade, do conceito jurídico indeterminado e do accountability nos programas de incentivo fiscal será a revisão bibliográfica para a acepção dos conceitos ora levantados, bem como a exposição do atual estado da arte envolvendo tal temática. Além disso, utilizar-se-á o método hipotético-dedutivo, construindo conjecturas com alta probabilidade de ocorrência, para a posterior análise da pertinência da hipótese lançada.

Nesse sentido, a hipótese a ser testada consiste justamente em que as leis instituidoras dos incentivos fiscais concedem alto grau de discricionariedade aos governantes através da 
previsão em larga escala de conceitos jurídicos indeterminados, sendo de suma importância o controle e o accountability para se evitar a malversação desses mecanismos.

Por fim, cabe salientar que a estrutura deste artigo assenta-se em seis capítulos, sendo o primeiro relativo à exposição dos três elementos jus administrativistas objeto deste estudo, enquanto no segundo será analisado os incentivos fiscais sob a ótica dual de tipo e conceito. Do terceiro ao quinto capítulo discorrer-se-á sobre cada um dos programas de incentivo instituídos pelo Estado de Goiás: o Fomentar, o Produzir e o Pró Goiás, respectivamente. Em seguida, no capítulo sexto, concretizando o método hipotético-dedutivo, constatar-se-á a incidência da premissa maior, qual seja, a discricionariedade, o conceito jurídico indeterminado e o accountability, sobre a menor, isto é, os programas de incentivo fiscal em análise. Por fim, na conclusão serão expostos os resultados obtidos desta pesquisa.

Adentra-se, agora, na compreensão dos conceitos administrativistas e tributários necessários para a análise que se propõe realizar.

\section{DISCRICIONARIEDADE, CONCEITO JURÍDICO INDETERMINADO E ACCOUNTABLITY NO ATUAL ESTÁGIO DO DIREITO ADMINISTRATIVO}

Oportuno destacar, primeiramente, que a presente pesquisa assenta-se fundamentalmente na concepção de tipo e conceito suscitada pela doutrina tributária especializada (ÁVILA, 2018, p. 11) mas de grande valia e aplicabilidade para os termos jus administrativistas que consistem no cerne deste estudo.

Dessa forma, a acepção conferida ao termo tipo deve ser tratada como "a descrição de características habituais que costumam comumente ocorrer, devendo ser analisadas em conjunto" (ÁVILA, 2018, p. 12), de modo que tal expressão se limita a descrever propriedades típicas que constantemente são observadas, não sendo, todavia, tais propriedades necessárias e suficientes para a verificação do tipo.

Nessa perspectiva, quando determinada categoria é compreendida como tipológica, implica dizer que é possível expor determinadas características genéricas a ela relativas. Contudo, caso ausente alguma dessas características, a identificação da categoria em questão não estará comprometida por si só, podendo ser observada diante da presença de outros elementos que servirão de substrato para sua individualização.

De maneira geral, a categoria tipológica terá maior grau de abstração e generalidade, podendo ser constatada sua ocorrência a partir da presença de propriedades que comumente, porém não necessariamente, ocorrem.

Ao contrário, o termo conceito traz a ideia de propriedades necessárias e suficientes para sua verificação, no sentido de que sem determinada propriedade o conceito não se manifesta, do mesmo que com tais propriedades o conceito se confirma (ÁVILA, 2018, p. 11). A consequência disso é que, ao contrário da concepção de tipo, o conceito será composto por estruturas rígidas, limitadas e exaustivas. 
Desse modo, a categoria conceitual estará presente apenas quando todos os elementos que consistem em seus requisitos estiverem presentes, o que confere maior grau de concretude a essa categoria, distinguindo, nesse ponto, sobremaneira da categoria tipológica.

Na seara tributária a ideia de conceito pode ser facilmente constatada, diante do fato de que sua essência é ser composta por normas que visam à limitação ao poder estatal de tributar. Assim, o próprio fato gerador no Direito Tributário, por exemplo, é categoria conceitual, porque, caso não se faça presente determinado elemento necessário e suficiente para sua ocorrência, tal fato não se concretizará e a obrigação tributária não nascerá.

Neste estudo, todavia, a despeito da natureza tributária intrínseca aos incentivos fiscais, estes serão analisados sob a ótica de estruturas que se inserem, primordialmente, na seara jus administrativista, em razão de ambos os ramos se filiarem ao Direito Público e, dessa forma, terem regime jurídico semelhante em alguns aspectos.

Dentre esses aspectos que permitem a comunicação entre Direito Tributário e Administrativo emerge a concepção que se tem dos termos discricionariedade, conceito jurídico indeterminado e accountability, os quais ganham considerável relevância no tocante aos incentivos fiscais, pois, por meio deles, o controle jurídico da instituição e execução desses benefícios poderá ser concretizado.

Nesse contexto, é fundamental se compreender que os três termos jus administrativas em comento são de categoria tipológica, de modo que os elementos estruturantes de tais expressões são fluidos, ilimitados e exemplificativos.

Essa distinção é fundamental para que se possa compreender o controle dos incentivos fiscais de maneira mais apropriada, especialmente diante do fato de que não se observar uma estrutura rígida para a configuração do accountability ou do conceito jurídico indeterminado, de modo que a discricionariedade do governante, nesse aspecto, deve ser criteriosamente controlada e fiscalizada, sob pena de nefasta malversação dos incentivos fiscais, o que gera consequências consideravelmente perversas às finanças públicas, à economia estadual e, consequentemente, às condições sociais.

Adentrando especificamente na análise de cada categoria tipológica em estudo, cabe ressaltar, a respeito da discricionariedade, que esta se manifestará nas hipóteses em que o poder da Administração puder adotar a solução casuística com base em critérios de oportunidade, conveniência, justiça e equidade, diante da ausência de definição conceitual por parte do legislador (DI PIETRO, 2016, p. 254).

Deve-se, no entanto, pontuar que tal perspectiva da discricionariedade não pressupõe que o poder é ilimitado; ao contrário, a liberdade de atuação do administrador público encontrará limitação traçada pela lei.

De todo modo, o controle da discricionariedade do agente competente, ainda que mereçam ser respeitados o mérito administrativo e o juízo político, apresenta considerável importância, diante do poder jurídico que é conferido a tal agente.

A compreensão desse poder remonta à expansão da legalidade (DI PIETRO, 2012, p. 3), que, ao reger toda a estrutura do Estado de Direito, limita o poder dos representantes estatais, emergindo a discricionariedade como vasto espaço de atuação do agente público em 
sentido amplo, o qual passa a deter considerável parcela de poder jurídico para o exercício de sua competência.

Nesse contexto emerge a compreensão tipológica de conceito jurídico indeterminado. Este surge no debate jurídico a partir da teoria dos motivos determinantes, a qual limitava a discricionariedade administrativa na medida em que possibilitava ao Poder Judiciário o exame da legalidade dos motivos suscitados pelo administrador (DI PIETRO, 2012, p. 10).

A consequência disso foi a apreciação dos fatos, seguida, posteriormente, da qualificação jurídica dos mesmos apresentados na motivação pelo administrador público. Com isso, tornou-se possível o exame dos conceitos jurídicos indeterminados, termos com sentidos amplos e abertos, eminentemente tipológicos, sendo compreendido, em suma, como a outorga de discricionariedade à Administração Pública (DI PIETRO, 2012, p, 10). De todo modo, na medida em que se concedia ao Poder Judiciário o exame dos conceitos jurídicos indeterminados utilizados pelo administrador público, houve a natural redução da discricionariedade administrativa, passando esta a conviver com maiores limitações e controle.

Do outro lado da perspectiva da atuação do administrador público, momento no qual se encontra a manifestação da discricionariedade e da concretização e preenchimento de conceitos jurídicos indeterminados, apresenta-se a ideia de accountability, voltada, sobretudo, para a ideia de prestação de contas, responsabilização (MARQUES NETO, 2010, p. 2).

Deve-se ressaltar que o poder discricionário é prerrogativa fundamental para o Estado Social Democrático de Direito que se constrói. Isso porque somente através da liberdade de atuação do administrador público se poderá pensar, elaborar, construir e concretizar políticas públicas eficientes e efetivas para a garantia de direitos assegurados pelo ordenamento jurídico.

Dessa maneira, a atuação plenamente vinculada da Administração Pública não atende às necessidades e demandas de uma sociedade altamente complexa como a atual. 0 poder discricionário do gestor público emerge justamente nesse momento, diante da possibilidade de escolha, conforme critérios de conveniência e oportunidade, dos mecanismos jurídicos a serem elaborados e concretizados pela Administração Pública.

Ocorre que, conforme já demonstrado, a atuação da Administração Pública, quando imbuída de discricionariedade, não pode ocorrer de maneira ilimitada. A concepção de conceitos jurídicos indeterminados emergem justamente em virtude dessa celeuma, visando conferir prerrogativas de controle pelo Poder Judiciário na tarefa de apreciar atos do administrador público dotados de discricionariedade.

Da mesma forma, ainda que discricionária determinada escolha, esta deverá atender aos requisitos de controle estabelecidos em lei, sendo corolário dessa exigência o que se conceitua como accountability, isto é, a prestação de contas e a responsabilização do gestor público pelos atos elaborados.

No presente caso, tais elementos assumem contornos de mais alto relevo, tendo em vista a abertura que assumem os incentivos fiscais, desde seus pressupostos jurídicos e fáticos, passando pelos mecanismos fornecidos pelo ordenamento jurídico para sua elaboração e findando-se no âmbito do controle que deverá ser realizado posteriormente à sua concessão. 
Diante de todo o exposto, deve-se ressaltar a relevância dos tipos aqui apresentados, em decorrência do fato de que, ainda que a atuação do administrador público no que se refere à concessão de incentivos fiscais seja discricionária, ela não poderá ser tida como arbitrária, devendo-se estabelecer limites e critérios, com base no preenchimento dos conceitos jurídicos indeterminados que circundam a matéria, assim como com a estipulação de um criterioso e límpido accountability por parte da autoridade administrativa concessora de tais incentivos.

\section{INCENTIVOS FISCAIS-FINANCEIROS - COMPREENSÃO NORMATIVA E TIPOLOGIAS}

Compreendidos os termos tipológicos administrativistas fundamentais para esta pesquisa, adentra-se agora na seara preponderantemente tributária e financeira, a partir do estudo dos incentivos fiscais, tanto em sua perspectiva conceitual, como através da compreensão de suas tipologias.

Tradicionalmente, o tributo é tido a partir de sua finalidade fiscal, voltado para a arrecadação e fornecimento de receitas públicas ao Estado, para que este possa executar e adimplir as obrigações contraídas. Nessa perspectiva, se tem a compreensão de Estado Tributário Distribuidor, sendo o ente que tributa os que mais possuem, na medida do possível, para repassar aos que mais necessitam, seja através dos serviços ou bens públicos, seja por meio pecuniário propriamente dito (MACHADO; MOREIRA, 2019, p. 157).

Através da concepção fiscal do tributo, este assume papel prioritário no financiamento dos direitos fundamentais (CORREIA NETO, 2019, p. 185). Isso porque os recursos públicos arrecadados pelo recolhimento dos tributos exigidos do contribuinte serão, posteriormente, revertidos para o financiamento das mais diversas obrigações assumidas pelo Estado, destacando-se, nessa perspectiva, a efetivação dos direitos fundamentais, sejam os relacionados com a defesa, com a participação ou com a prestação concreta por parte do ente estatal.

No entanto, o tributo não assume finalidade exclusivamente fiscal. Conforme entendimento pacífico da doutrina tributária, os tributos podem assumir também conotação extrafiscal, no sentido de estimular ou desestimular determinada atividade econômica (MACHADO, 2015, p. 36). Assim, é justamente nessa acepção tributária que emerge o fenômeno dos incentivos fiscais.

Dessa maneira, os incentivos fiscais manifestam-se como instrumento previsto na Constituição Federal para o combate da desigualdade interna do país, possibilitando o desenvolvimento regional de modo amplo e igualitário. Nessa perspectiva, o desenvolvimento deve ser encarado não apenas como um elemento de ordem quantitativa, mas sim equitativa, diferenciando-se, portanto, do mero crescimento econômico (BERCOVICI, 2003, p. 103).

Assim, os incentivos fiscais se manifestarão a partir da tributação sob a perspectiva da função indutora, motivando o agente econômico como um fator de alavancagem do desenvolvimento econômico de determinada região do país (BEVILACQUA, 2013, p. 162). 
Deve-se ressaltar que, ao contrário dos tipos apresentados no tópico supra (discricionariedade, conceito jurídico indeterminado e accountability), os incentivos fiscais apresentam característica conceitual, sendo termo de conotação fechada, composto por elementos necessários e suficientes para sua manifestação.

Tal acepção dos incentivos fiscais encontra-se em conformidade com o método constructivista lógico-semântico (PIVA, 2018, p. 36). Por meio deste, analisa-se o fenômeno jurídico a partir da linguagem (constructivismo), indicando análise sintática da língua na perspectiva lógica, bem como a relação dos signos com os objetos que se constrói (perspectiva semântica).

Com base nesse método, os incentivos fiscais são compreendidos como normas jurídicas que alteram a configuração da regra-matriz de incidência tributária, seja por meio de mudança no antecedente (critérios material, espacial e temporal), seja no consequente (pessoal e quantitativo), de modo que instarurar-se-á uma normatividade de indução e atração de investimento, atendendo, assim, à finalidade extrafiscal do tributo.

Compreendidos os aspectos conceituais dos incentivos fiscais, cabe agora mencionar as tipologias que tal fenômeno jurídico assume. Tal classificação é de grande relevância, em especial no tocante aos programas Fomentar, Produzir e Pró Goiás, que podem assumir também perspectiva de incentivo financeiro e não meramente fiscal.

A relevância da devida compreensão dessa classificação aumenta na medida em que a Constituição Federal não assentou-se em rigoroso critério técnico para a definição e delimitação dos incentivos fiscais. Assim, encontra-se no texto constitucional as expressões

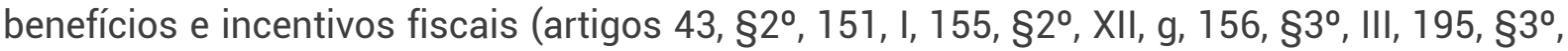
$227, \S^{\circ}$, VI, CF e artigos 40, 41 e 88, II, ADCT) indicando, em suma, o mesmo fenômeno, ainda que divergentes tais conceitos.

Portanto, por benefícios fiscais devem-se compreender normas jurídicas que interferem na regra matriz de incidência tributária, diminuindo ou eliminando o montante pecuniário devido, sem, contudo, buscar induzir a conduta do contribuinte. Assim, é o caso de benefícios concedidos a título de isenção de IRPF (art. $6^{\circ}$, Lei Federal n. 7.713/1988), os quais não possuem o intuito de induzir a conduta do contribuinte.

Ao contrário, os incentivos fiscais manifestam-se também pela interferência na regra matriz de incidência tributária, diminuindo ou eliminando o montante pecuniário devido, porém, com a finalidade extrafiscal, de indução do comportamento do agente privado. Já os incentivos financeiros diferenciam-se dos fiscais, já que não encontram-se no âmbito do Direito Tributário, na medida em que concedem privilégios após a extinção da obrigação tributária, estando, portanto, tais relações imbuídas de caráter extra tributário (PIVA, 2018, p. 195).

Dessa maneira, compreendidas as acepções conferidas aos incentivos fiscais em sentido lato, adentra-se, agora, na análise de cada um dos programas objeto deste estudo. 


\section{O PROGRAMA FOMENTAR}

Compreendidos os aspectos teóricos que fundamentam esta pesquisa, cabe agora adentrar especificamente no estudo dos programas de incentivo financeiro-fiscal de ICMS estabelecidos pelo Estado de Goiás ao longo das últimas décadas, a começar pelo Fomentar, promulgado pela Lei Estadual n. 9.489, de 19 de julho de 1984.

Dessa forma, por meio do mencionado ato legislativo goiano, restou estabelecido o Fomentar, Fundo de Participação e Fomento à Industrialização do Estado de Goiás, criado com o escopo de incrementar o setor industrial do Estado, seja através da implantação, seja por meio da expansão de atividades já existentes (GOIÁS, 1984, artigo $1^{\circ}$ ).

Dessa forma, se observa, desde já, que o escopo de tal incentivo fiscal-financeiro consiste justamente no desenvolvimento do setor industrial da economia goiana, partindo-se do pressuposto de que tal área produtiva necessitaria de estímulos por parte do ente estatal para que pudesse ser mais e/ou melhor desenvolvida.

Para a composição desse fundo, a lei elencou como fontes o Tesouro Estadual, créditos orçamentários destinados pelo Poder Público, recursos colocados à sua disposição por instituições públicas ou privadas, rendimentos provenientes de suas operações (encargos financeiros, reembolso de capital e outros), produto de alienação de ações, debentures e outros títulos ou bens adquiridos ou incorporados ao Fundo e rendas oriundas de títulos mobiliários.

É importante salientar tal aspecto para destacar, primordialmente, a natureza e a origem das verbas que compõe o fundo em comento, de modo que, tratando-se de finanças públicas, o controle deve ser rigoroso, em decorrência do fato de que o Estado necessita de estar com saúde financeira para que possa efetivar os direitos a que se obrigou (HOLMES; SUSTEIN, 1999, p. 23).

Por fim, a referida lei estabeleceu também (GOIÁS, 1984, artigo 8) a criação do ConseIho Deliberativo, composto por secretários de Estado, representantes de federações e sindicato, bem como da Diretoria Executiva, a cargo do Banco de Desenvolvimento do Estado de Goiás, os quais exerceriam a administração do Fomentar.

Essa estrutura administrativa deve, desde já, ser realçada, pois, conforme se constatará adiante, consiste em um dos aspectos centrais da pesquisa. Isso porque a lei confere poderes ao Conselho Deliberativo do Fomentar, especialmente para a suspensão e revogação dos benefícios concedidos (GOIÁS, 1990, artigo 6²).

Ocorre que a criação de tal fundo ainda não serviu para a alavancagem do setor industrial do Estado de Goiás. Desse modo, seis anos depois, foi promulgada a Lei Estadual n. 11.180, de 19 de abril de 1990, estabelecendo modificações no programa Fomentar e criando, assim, o incentivo financeiro-fiscal que buscaria a indução dos agentes econômicos para o desenvolvimento desse setor da economia goiana.

A diferença, portanto, consistia no fato de que a lei promulgada no ano de 1984 apenas criou o fundo Fomentar, porém foi apenas em 1990 que o incentivo fiscal-financeiro foi criado. 
Nesse contexto, foram estabelecidos quatro estímulos aos empreendimentos industriais goianos (GOIÁS, 1990, artigo $2^{\circ}$ ): (i) venda de terrenos nos distritos industriais do Estado, (ii) edificação de obras de construção civil em áreas urbanas de propriedade do Estado de Goiás consideradas de alta relevância para o desenvolvimento regional, (iii) pagamento do ICMS pela alíquota de 7\% (sete por cento) nas operações que realizarem com outros estabelecimentos industriais também beneficiários do programa com produtos de fabricação própria e abarcados pelo projeto aprovado no Conselho Deliberativo do Fomentar e, enfim, (iv) empréstimos de até $70 \%$ (setenta por cento), via recursos orçamentários, do ICMS que a empresa tiver de recolher ao erário estadual, excetuado o imposto decorrente de saída de mercadoria a título de bonificação, doação, brinde ou operação semelhante, sendo este o cerne do programa.

Tal previsão legal estabelece, assim, relação de ordem jurídico financeira, já que o beneficiário manterá o recolhimento integral do ICMS devido; contudo, tal adimplemento se dará por meio de financiamento perante o agente competente mantido pelo Estado. Nos dizeres de Lucas Bevilacqua (BEVILACQUA, 2013, p. 64), essa prática pode ser sintetizada da seguinte forma: "o contribuinte quita a obrigação tributária com o empréstimo tomado perante o agente financiador, formando uma segunda relação jurídica de natureza não tributária".

Em decorrência dessa sistemática que o incentivo do Fomentar tem natureza fiscal-financeira, e não meramente tributária, já que extrapola a relação jurídico-tributária entre Estado e sujeito passivo.

Por fim, cabe destacar ainda que, assim como os demais programas em análise, o Fomentar pode ser taxado como incentivo a custo zero (BEVILACQUA, 2013, p. 177). Este implica na concessão de determinado estímulo para empreendimentos antes inexistentes, de modo que a corrente arrecadação tributária não sofrerá qualquer impacto direto advindo desse incentivo, o qual atual exclusivamente sobre o ICMS novo gerado.

\section{O PROGRAMA PRODUZIR}

Visando expandir os efeitos advindos do programa Fomentar, o Estado de Goiás, visando incrementar sua política desenvolvimentista do setor industrial, criou o programa Produzir, através da Lei Estadual n. 13.591, de 18 de janeiro de 2000, tido como o novo instrumento de execução da política industrial do Estado de Goiás.

Para que determinado agente privado possa usufruir do incentivo em análise, a lei estabelece como critério de enquadramento a apresentação de projeto de viabilidade econômico-financeira que atenda aos requisitos relativos aos beneficiários e às prioridades determinadas pela lei (GOIÁS, 2000, artigo $4^{\circ}$ ).

A avaliação de tal projeto caberá à Comissão Executiva do Produzir, esfera com competência para a aprovação de tais requerimentos. Mais uma vez, importante destacar esse aspecto, tendo ciência da estrutura administrativa que tais programas apresentam para a tomada de decisões. 
Nesse contexto, destaca-se que o Produzir prevê a criação de dois centros de competência administrativa em sua estrutura: a Comissão Executiva e o Conselho Deliberativo. A diferença entre ambas, além das competências previstas na lei ${ }^{4}$, consiste na composição de cada: enquanto a primeira possui quatro representantes do Estado (sendo três secretários de Estado e o Diretor-Presidente da Agência de Fomento S.A.) e três da sociedade civil, o Conselho Deliberativo apresenta doze representantes do Estado e onze da sociedade civil.

Conforme restará melhor delineado e aprofundado a seguir, pode-se constatar que a abertura do programa Produzir para a sociedade civil consiste em válido e importante mecanismo de legitimação democrática, tendo em vista que possibilita a participação de representantes da sociedade civil na tomada de decisões do programa.

Estabelecida a concessão do incentivo, o beneficiário poderá usufruir dos seguintes benefícios, nos termos aprovados pelo Conselho competente do Produzir (GOIÁS, 2000, artigo 20): (i) financiamento de até $73 \%$ (setenta e três por cento) do ICMS devido ao Tesouro Estadual advindo de operações industriais próprias; (ii) subvenção para investimento de até $100 \%$ (cem por cento), caso se destine à ampliação ou à modernização do parque industrial; e (iii) pagamento do ICMS pela alíquota de $7 \%$ (sete por cento) nas operações com produtos de fabricação própria que realizarem com outros estabelecimentos industriais beneficiários do programas Fomentar ou Produzir. Percebe-se, mais uma vez, que o atrativo prioritário do programa é o financiamento do ICMS devido ao Estado de Goiás, assim como se processava com o Fomentar, porém, dessa vez, no montante de até $73 \%$ (setenta e três por cento).

Ocorre que sobre tal incentivo financeiro-fiscal o beneficiário deverá realizar os seguintes pagamentos (GOIÁS, 2000, artigo 20): (i) adiantamento de, no mínimo, 10\% (dez por cento) do valor da parcela de ICMS incentivado mensal; (ii) incidência de juros de até 0,2\% (dois décimos por cento) ao mês, não capitalizáveis, cujo pagamento será feito mensalmente; e (iii) recolhimento de $15 \%$ do ICMS incentivado ao Fundo Protege ${ }^{5}$ (GOIÁS, 2003, artigo $9^{\circ}$ ).

Nesse ponto cabe destacar que o Fundo Protege consiste em verbas destinadas à prestação de serviços sociais, especialmente das áreas de nutrição, habitação, saúde, educação, saneamento básico, assistência social, reforço de renda familiar (GOIÁS, 2003, artigo $1^{\circ}$ ). Em suma, trata-se de um mecanismo criado pelo Estado de Goiás em criar um fundo voltado

4 Lei Estadual n. 13.591/2000: Art. 11 - O Conselho Deliberativo terá as seguintes atribuições: I - aprovar a programação, o orçamento e o relatório anuais; II - estabelecer as diretrizes, prioridades e estratégias de atuação; III - apresentar, anualmente, ao Chefe do Poder Executivo, relatórios circunstanciados sobre a execução e os resultados auferidos pelo PRODUZIR; IV - sugerir ao Poder Executivo modificações no disciplinamento jurídico do PRODUZIR; V - autorizar a utilização dos recursos do FUNPRODUZIR, promovida pela Superintendência do Fomentar/Produzir da Secretaria de Indústria e Comércio, visando atender a programas de interesse para o desenvolvimento do Estado; VI - outras atribuições de ordem geral. Art. 12. O Conselho Deliberativo terá uma Comissão Executiva constituída pelos Secretários de Estado de Desenvolvimento Econômico, Científico e Tecnológico e de Agricultura, Pecuária e Irrigação, da Fazenda, de Gestão e Planejamento e pelo Diretor-Presidente do Agente Financeiro do Programa PRODUZIR, que representam o Estado de Goiás, e, ainda, pelos Presidentes da Federação das Indústrias do Estado de Goiás e da Associação Pró-Desenvolvimento Industrial do Estado de Goiás - ADIAL, bem como por 02 (dois) membros eleitos pelos representantes das entidades da sociedade civil que dele participam, com as seguintes atribuições: I - elaboração das propostas anuais de programação e do orçamento; II - elaboração e apresentação ao Conselho Deliberativo do Relatório Anual das atividades do PRODUZIR; III - aprovação de normas e procedimentos operacionais; IV - aprovação de projeto e concessão de benefício; $V$ - acompanhamento de execução do PRODUZIR e dos projetos assistidos, em articulação com o Agente Financeiro e os outros órgãos governamentais envolvidos; VI - outras atribuições definidas no regulamento.

5 Lei Estadual n. 14.469/2003: Art. 9o Fica o Chefe do Poder Executivo autorizado a: II - condicionar a fruição de benefício ou incentivo fiscal, concedido por meio de lei estadual, à contribuição para o Fundo de que trata esta Lei correspondente ao percentual de até $15 \%$ (quinze por cento) aplicado sobre o montante da diferença entre o valor do imposto calculado com aplicação da tributação integral e o calculado com utilização de benefício ou incentivo fiscal 
exclusivamente à prestação de atividades assistenciais, de modo que todo o regramento conferido à execução orçamentária possa ser diminuído.

Ainda, importante destacar que, a despeito de, à primeira vista, a renúncia fiscal envolvida ser na casa dos $70 \%$ (setenta por cento), o incentivo efetivo restará estabelecido em montante bem inferior, diante de todas as regras de contrapartida que a legislação estabelece para se usufruir do benefício em comento.

Outro aspecto de grande relevância da lei do Produzir consiste no estabelecimento de critérios objetivos para se usufruir integralmente o valor do imposto financiado (GOIÁS, 2000, artigo 20-A). Nesses termos, a lei prevê fatores de desconto que atuarão sobre o montante de financiamento firmado entre o Poder Público e o particular, sendo tais fatores ligados à adimplência, à aquisição de determinadas mercadorias, à manutenção de emprego, a questões de ordem ambiental e ao investimento em determinados setores de atuação estatal por parte do beneficiário do Produzir.

0 regramento referente aos ditos fatores de desconto consiste em mecanismo voltado para assegurar o gozo eficiente e responsável do incentivo por parte dos beneficiários, tendo em vista que não bastará a obtenção do benefício em comento, devendo ter que apresentar, mensalmente, o cumprimento dos fatores de desconto a que se obrigou atender, sob pena de o incentivo sofrer sensível afetação e diminuição.

Por fim, deve-se indicar, a respeito da estrutura e procedimentalização do Produzir a criação e atuação da Agência de Fomento de Goiás S.A., enquanto Agente Financeiro do programa. Isso porque a obtenção do benefício em comento somente se concretiza com a estipulação do contrato junto a tal pessoa jurídica, sendo que esta irá atuar como o agente financiador do incentivo.

\section{O PROGRAMA PRÓ GOIÁS}

Após a duração de vinte anos do programa Produzir, o Estado de Goiás estabeleceu seu novo programa de incentivo fiscal, o Pró Goiás, por meio da Lei Estadual n. 20.787, de 03 de junho de 2020. Tal programa foi elaborado com fundamento em três critérios prioritários, quais sejam, o alinhamento à Lei Complementar n. 160/2017, a busca pela maior desburocratização dos incentivos fiscais e o combate à insegurança jurídica nesse setor.

Dessa maneira, cabe salientar inicialmente que o norte prioritário do novo programa de incentivo fiscal do Estado de Goiás remonta à disciplina conferida pela Lei Complementar $\mathrm{n}$. 160, de 7 de agosto de 2017 às isenções e aos incentivos e benefícios fiscais ou financeiro-fiscais. Com fulcro nessa norma, restou criada a possibilidade de Estados membros aderirem a programas de incentivo fiscal concedidos por outros Estados componentes da mesma região, durante o prazo que durar o benefício na unidade federada criadora (BRASIL, 2017, artigo $3^{\circ}$ ). Assim sendo, com base na adesão à Lei Complementar n. 93/2001 e à Lei Estadual n. 4.049/2011, ambas do Estado do Mato Grosso, o Estado de Goiás criou o mencionado programa Pró Goiás. 
Como os seus antecessores históricos, o Pró Goiás busca o desenvolvimento socioeconômico do Estado através da implantação, da ampliação e da revitalização dos estabelecimentos industriais de seu território, de modo que o enquadramento dos beneficiários se dará com base nessas categorias. (GOIÁS, 2020, artigo $3^{\circ}$ ).

A respeito dos incentivos concedidos, o programa prevê a concessão de crédito outorgado, conotando, assim, tratar-se, dessa vez, de incentivo eminentemente fiscal, e não mais financeiro-fiscal. 0 crédito outorgado a ser concedido poderá ser de duas categorias, considerando sempre o valor positivo resultante do confronto entre os débitos e os créditos do imposto: (i) de $67 \%$ (sessenta e sete por cento) para o estabelecimento que se localizar em município tido como prioritário (a ser determinado em regulamento), optar por metas de arrecadação ou que pertencer a empresa cuja receita bruta anual não ultrapasse o limite de enquadramento do Simples Nacional; ou (ii) variável entre 64\% (sessenta e quatro por cento) a $66 \%$ (sessenta e seis por cento), conforme a decorrência do tempo de fruição do incentivo, pelo período de até 12 (doze) meses, de 13 (treze) a 24 (vinte e quatro) meses (percentual de $65 \%$ ) ou a partir do $25^{\circ}$ (vigésimo quinto) mês, respectivamente (GOIÁS, 2020, artigo $5^{\circ}$ ). Ainda, restou possibilitada também, mediante autorização de decreto específico, a substituição do crédito outorgado em comento pela fruição de crédito presumido, desde que o interessado tenha se enquadrado como beneficiário do programa e seja concedida para o creditamento de aquisição de matéria-prima, material secundário, insumos e materiais de acondicionamento.

De todo modo, para se usufruir de tal incentivo, o beneficiário deverá apresentar como contrapartida: (i) recolhimento ao Fundo Protege Goiás do percentual de 10\% (dez por cento), $8 \%$ (oito por cento) ou 6\% (seis por cento), conforme o período de fruição do programa, considerando o valor concedido pelo incentivo; (ii) a realização dos investimentos assumidos; e (iii) o deferimento do pedido pelo Conselho de Desenvolvimento Industrial do Estado de Goiás, ouvidas as Secretarias de Estado da Indústria, Comércio e Serviços e da Economia, sendo que o requerimento realizado deverá estar de acordo com o programa Pró Goiás e atender aos critérios de conveniência e oportunidade do interesse público (GOIÁS, 2020, artigo 11).

Para a fruição do referido o incentivo, o estabelecimento beneficiário não poderá gozar dos incentivos Fomentar ou Produzir, tampouco exercer determinadas atividades produtivas elencadas pela lei em análise (GOIÁS, 2020, artigo $6^{\circ}$ ). Ocorre que, a despeito de tais limitações legais, restou estabelecida a prerrogativa do Chefe do Poder Executivo, via decreto estadual, fundado em relevante interesse econômico, social, fiscal ou de melhoramento da cadeia produtiva goiana, afastar tais vedações.

Percebe-se, desde já, que a lei do Pró Goiás apresenta notória distinção com relação aos seus programas antecessores, sendo a maior concentração de poderes nas mãos do Governador do Estado a principal delas, em contraposição à maior desconcentração decisória para o Conselho Deliberativo e a Comissão Executiva previstas no Produzir.

Dessa forma, a existência de esses dois órgãos consultivos e decisórios é substituída pela presença do Conselho de Desenvolvimento Industrial do Estado de Goiás (GOIÁS, 2020, artigo 15), composto pelo Governador e quatro secretários de Estado. A abertura para a participação da sociedade civil somente ocorre, agora, através do Conselho Consultivo, composto por oito representantes civis, porém tendo sua estrutura ligada ao Conselho de Desenvolvi- 
mento Industrial, sem poder decisório e tendo suas atribuições estabelecidas, mais uma vez, por decreto do Governador.

Por outro lado, estabelecendo como obrigações a serem seguidas pelo beneficiário do programa, a lei do Pró Goiás determina que o contribuinte será o substituto tributário para trás com relação aos produtos primários adquiridos, ao mesmo tempo em que prevê a possibilidade de realizar a liquidação do ICMS incidente na importação de matéria-prima, material secundário e ativo imobilizado mediante lançamento a débito na escrituração fiscal. A respeito desta última permissão, a lei, mais uma prevê, prevê ao Governador do Estado a prerrogativa de excluí-la, considerando condições de mercado (GOIÁS, 2020, artigo 6º).

De todo modo, diante da estrutura do novo programa de incentivo do Estado de Goiás, constata-se que a busca pela desburocratização se confere através, sobretudo, das seguintes mudanças: extinção dos poderes decisórios dos conselhos com representantes da sociedade civil, concentração de poder nas mãos do Governador, bem como de seus representantes direto, extinção da Agência de Fomento S.A. enquanto agente financeiro e substituição de um incentivo de natureza financeira para um de índole exclusivamente tributária.

A despeito do escopo de busca por maior segurança jurídica e menos burocracia, tais mudanças podem se manifestar prejudiciais à execução do incentivo fiscal em questão, especialmente diante da concentração dos poderes decisórios e da própria redução de burocracias administrativas, as quais serviam para o beneficiário também como um instrumento de defesa em face de possíveis arbitrariedades do Poder Executivo. No entanto, tais aspectos serão devidamente analisados no capítulo seguinte.

\section{OS PROGRAMAS DE INCENTIVO FINANCEIRO- FISCAL DO ESTADO DE GOIÁS NA PERSPECTIVA DO ATUAL DIREITO ADMINISTRATIVO}

Diante de todo o exposto acima, destacando-se e analisando as peculiaridades básicas de cada programa em estudo, demonstrando o percurso adotado pelo Estado de Goiás desde a década de 1980, na tentativa de fomento a seu parque industrial, compreende-se que o Pró Goiás manifesta-se, de fato, como um programa inovador e que muda o paradigma de atuação do Estado goiano, ainda que o norte comum de todos os incentivos persista.

As alterações advindas do Pró Goiás frente ao Fomentar e ao Produzir podem ser divididas criticamente em três grupos: a natureza do incentivo fiscal concedido, o montante do benefício efetivo e a estruturação das competências administrativas para reger o programa.

Dessa maneira, urge salientar, primeiramente, a respeito da natureza dos incentivos. Enquanto os programas Fomentar e Produzir consistiam em benesses de caráter fiscal-financeiro, já que além da relação tributária entre beneficiário e Estado existia também a relação contratual entre o primeiro e o agente financeiro do programa, o Pró Goiás se caracteriza por ser um incentivo de índole exclusivamente fiscal, por tratar-se de crédito outorgado de ICMS, de modo que a Agência de Fomento S.A. nem mesmo existe mais nesse programa. 
No entanto, o cerne deste estudo remonta às outras duas alterações advindas do Pró Goiás. Assim, com relação ao aspecto quantitativo dos programas em análise, isto é, deve-se, de imediato, analisar o quantum que as respectivas leis estaduais preveem de incentivo para os beneficiários. Isso porque o poder de determinado programa de incentivo fiscal manifesta-se, justamente, com fulcro na maior ou menor quantidade de carga tributária incentivada, tornando-se, com isso, instrumento político de maior ou menor alcance com base nesse quesito.

Nesse sentido, conforme demonstrado acima, o programa Fomentar concede incentivo financeiro de $70 \%$ sobre o ICMS novo gerado pelo beneficiário, sendo que as contrapartidas serão: recolhimento de 15\% (quinze por cento) sobre o valor incentivado para o Fundo Protege, incidência de juros de $0,2 \%$ (dois décimos por cento) ao mês sobre o valor financiado e correção monetária de $25 \%$ (vinte e cinco por cento) do montante restante a ser beneficiado.

Dessa maneira, pode-se concluir que o incentivo final do Fomentar remonta ao percentual aproximado de $59,38 \%$ (cinquenta e nove inteiros e trinta e oito centésimos por cento) de incentivo financeiro efetivo, desconsiderando a correção monetária anual que deverá incidir sobre o benefício.

Com relação ao programa Produzir, o incentivo financeiro concedido será de até $73 \%$ (setenta e três por cento) sobre o ICMS gerado pelo beneficiário. Como contrapartidas, a lei prevê: 15\% (quinze por cento) sobre o valor incentivado para o Fundo Protege, incidência de juros de $0,2 \%$ (dois décimos por cento) ao mês sobre o valor financiado e a antecipação de $10 \%$ (dez por cento) sobre o montante beneficiado. Considerando todos esses valores, o incentivo efetivo final será de aproximadamente $54,64 \%$ (cinquenta e quatro inteiros e sessenta e quatro centésimos por cento) do ICMS novo que seria devido pelo beneficiários aos cofres estaduais.

Por fim, com relação ao programa Pró Goiás, o incentivo, de natureza fiscal, concedido consiste em crédito outorgado de até $67 \%$ (sessenta e sete por cento), sendo que, como contrapartida, a lei estabelece até $10 \%$ (dez por cento) para o Fundo Protege na fruição exercida no primeiro ano de incentivo, reduzindo-se para $6 \%$ (seis por cento) a partir do terceiro ano.

Consequentemente, constata-se que no primeiro ano, o Pró Goiás concederá incentivo efetivo de $60,3 \%$ (sessenta inteiros e três décimos por cento), enquanto que a partir do terceiro ano, tal benesse subirá para $62,98 \%$ (sessenta e dois inteiros e noventa e oito centésimos por cento) de incentivo efetivo de ICMS.

Pelos números acima expostos, constata-se que o incentivo do Pró Goiás, a despeito das crescentes críticas feitas sobre o possível excesso na concessão de incentivos fiscais de ICMS, o que redundaria em elevada renúncia fiscal por parte do Estado, ainda que se trate de imposto que, via de regra, não seria gerado (GOIÁS, 2019, p. 12), é, em termos finais, percentualmente superior se comparado aos antecessores Fomentar e Produzir.

Dessa maneira, conforme abordado nesta pesquisa, o programa Pró Goiás, de fato, redunda em instrumento político de maior poderio, diante da concessão de benesse efetivamente superior a dos programas Fomentar e Produzir.

Ao mesmo tempo, percebe-se que a elaboração do novo programa de incentivo fiscal de Goiás, visando à redução de burocracias na concessão dos benefícios, extinguiu os antigos 
Conselhos Deliberativos, os quais teriam a incumbência de avaliar e aprovar os projetos econômicos apresentados, sendo compostos por representantes da sociedade civil.

Em troca, foi estabelecido Conselho de Desenvolvimento Industrial, composto exclusivamente por secretários de Estado. Assim, a antiga representatividade da sociedade civil organizada restou configurada apenas na previsão do Conselho Consultivo, o qual terá atribuições exclusivamente de assessoria na tomada de decisões, as quais ficarão a cargo do referido Conselho de Desenvolvimento.

Assim, a terceira alteração notável advinda do Pró Goiás remonta à redução de competência e, consequentemente, de representatividade da sociedade civil, concentrando os poderes em um órgão eminentemente político e com ligação direta ao Governo do Estado.

Ademais, constata-se também a redução da complexidade no tratamento do programa. No âmbito do Produzir havia toda uma estrutura administrativa, composta pelo Conselho Administrativo e Comissão Executiva, bem como a existência da Agência de Fomento S.A. para a celebração dos contratos de financiamento, além da necessidade de apresentação de projeto econômico de viabilidade. Ao contrário, na esfera do Pró Goiás, toda essa elaborada estrutura foi desconstruída: o Conselho e a Comissão sofreram as alterações acima expostas, a Agência de Fomento S.A. não tem mais atribuições (para este programa) e o projeto de viabilidade passa a ser, nos termos da lei, "simplificado", conforme modelo pré-estabelecido.

Por fim, porém não menos importante, complementando a análise aqui exposta, constata-se o aumento da competência do Chefe do Poder Executivo estadual sobre a execução do programa. Dessa maneira, se no contexto do Produzir restava prevista apenas uma específica atribuição ao Governador do Estado, o qual poderia estender os benefícios concedidos no âmbito do Microproduzir para estabelecimentos industriais enquadrados no Produzir, no contexto do programa Pró Goiás tais atribuições ganham maior relevo: (i) poder para afastar as vedações legais ao gozo do incentivo, com fundamento em critérios de relevante interesse econômico, social ou fiscal, (ii) permissivo para excluir a faculdade conferida pela lei aos beneficiários em liquidar o ICMS das matérias-primas e insumos adquiridos; (iii) determinação da procedimentalização das reuniões no âmbito dos Conselhos de Desenvolvimento Industrial e Consultivo e (iv) permissão para alterar o incentivo de crédito outorgado para presumido.

A consequência de todas essas alterações redunda, de fato, na redução da burocratização do incentivo, conforme objetivo político norteador do novo programa. Ocorre que tal redução implica, por outro lado, na diminuição de representatividade da sociedade civil nas decisões tomadas, bem como na atenuação da complexidade dos debates realizados. Toda essa transformação soma-se com o aumento de atribuições e a concentração de competências ao Chefe de Poder Executivo, o qual passa a gerir e influenciar diretamente o programa.

Descritas essa nova realidade da política fiscal do Estado de Goiás, cabe agora resgatar a compreensão desenvolvida a respeito das tipológicas (ÁVILA, 2018, p. 13) categorias definidas por discricionariedade, conceito jurídico indeterminado e accountability.

Com fundamento na concentração de maiores prerrogativas e atribuições ao Chefe do Poder Executivo, o legislador goiano conferiu considerável discricionariedade (DI PIETRO, 2012 , p. 4) na atuação do Governador no exercício de seu poder regulamentar. 
Tal discricionariedade é materializada através da utilização de conceitos jurídicos indeterminados (DI PIETRO, 2012, p. 10), tais como "relevante interesse econômico, social ou fiscal" (GOIÁS, 2020, artigo 6º ) ou mesmo através da definição de competência para delimitação de poderes a serem exercidos pelos órgãos de representação da sociedade civil organizada.

Soma-se a isso o fato de o programa Pró Goiás, a despeito de numericamente aparentar conceder incentivo de menor monta, o que, conforme análise acima, resta afastado, manifestar-se como um instrumento politicamente mais influente que seus antecessores, diante do aumento da carga tributária incentivada.

Portanto, além de a alteração da estrutura administrativa dos programas ter concentrado mais poderes nas mãos do Governador de Estado e seus Secretários, o aumento do poder político do Pró Goiás em decorrência do incentivo fiscal ser mais elevado também contribui para o alargamento do grau de discricionariedade dos administradores públicos.

Em síntese, com escopo de redução da burocratização, o Pró Goiás acabou por se tornar um programa que confere amplos poderes discricionários ao Governador e seus agentes imediatos (Secretários) através da utilização de conceitos jurídicos indeterminados em substituição da maior pluralidade assegurada pela participação de representantes da sociedade civil organizada na tomada de decisões.

Assim, para que não ocorra a malversação da política de incentivo fiscal e/ou financeiro-fiscal no Estado de Goiás, urge estabelecer critérios técnicos e o atendimento aos preceitos do accountability (MARQUES NETO, 2010, p. 2), devendo-se exigir a clara e detalhada prestação de informações das decisões tomadas no âmbito do Pró Goiás, sob pena de restar caracterizado nefasto retrocesso no controle das políticas públicas de incentivo fiscal.

Nessa perspectiva, o accountability ora defendido como critério de controle de fundamental importância para a garantia do eficiente manejo do programa Pró Goiás pode ser compreendido sob três perspectivas distintas (NASCIMENTO; RIBCZUK, 2015, p. 224), todas elas relacionadas com a exigência de uma gestão pública transparente: a prestação de contas por parte do agente público, a responsabilização pelos atos praticados e o controle social.

A primeira perspectiva acima destacada remonta à compreensão do accountability como ato de um indivíduo para com o Estado (SIU, 2011, p. 122). Nesse caso consiste na prestação de contas que deve ser realizada de maneira criteriosa e sistemática pelo Governador e/ou Secretários de Estado quando realizarem qualquer tomada de decisões no âmbito do Pró Goiás, devendo cada uma dessas decisões estar devidamente fundamentada e coadunada com o interesse público envolvida na questão.

Já com relação à acepção de accountability sob a ótica da responsabilização, está deverá ser efetiva e ocorrer quando restar configurada a adoção de conduta que viole as finanças públicas estaduais, que desrespeite à isonomia ou a legalidade tributária no contexto da concessão de incentivos fiscais ou que extrapole o poder discricionário que cada agente competente possui, tendo em vista que discricionariedade não pode ser confundida com arbitrariedade (DI PIETRO, 2016, p. 255).

A terceira perspectiva exposta remonta à ideia de ato do Estado para a sociedade (SIU, 2011 , p. 122), revelando a garantia do acesso e da publicidade da informação. Nesse con- 
texto, emerge a questão que envolve a responsividade, enquanto princípio basilar do Direito Administrativo Contemporâneo.

Nessa seara, compreende-se por responsividade a atuação instrumental da democracia na seara administrativa, conferindo legitimidade democrática e conciliação com a expressão da vontade popular nas decisões tomadas pelos administradores públicos (SAMPAIO, 2015, p. 10).

Constata-se que a escolha legislativa feita pelo Pró Goiás, no que se refere à excessiva redução de competências para os órgãos de representação social existentes no âmbito do Produzir, retirando-Ihes sua capacidade decisória e tornando-os estruturas meramente consultivas, é conduta que, em tese, diminui sensivelmente a responsividade presente nos programas de incentivo fiscal no Estado de Goiás, tendo em vista que a legitimidade democrática advinda da participação de diversos representantes da sociedade civil organizada é por demasiado abalada.

Portanto, observa-se também que a escolha por redução de burocracia consistiu, em suma, na diminuição considerável tanto da legitimidade democrática quanto da abertura dos programas de incentivo fiscal à sociedade civil goiana. Ainda que válida do ponto de vista legal, essa mudança deverá ser efetivada com asseio e rigorosidade, não sendo admissível que a maior discricionariedade dos poderes do Chefe do Poder Executivo no âmbito do Pró Goiás torne a política de incentivo fiscal do Estado goiano mero instrumento a serviço de interesses políticos.

\section{CONCLUSÓES}

O presente estudo, tendo como base hipotética a ideia de que as leis instituidoras dos incentivos fiscais concedem alto grau de discricionariedade aos governantes através da previsão em larga escala de conceitos jurídicos indeterminados, o que torna de fundamental importância o controle e o accountability para se evitar a malversação desses mecanismos, pôde concluir que, de fato, será justamente mediante criteriosa sistematização do accountability que a discricionariedade conferida pelos programas de incentivo fiscal não comprometerá a eficiência e a efetividade de tais incentivos, em especial o Pró Goiás, que elevou sensivelmente tal característica por meio da concentração de poder na cúpula do Poder Executivo estadual.

Para que se tornasse possível se alcançar tal resultado, foi-se necessário, primeiramente, obter a compreensão de determinados aspectos conceituais que consistem no substrato teórico desta pesquisa.

Dessa maneira, a distinção entre tipo e conceito e o enquadramento dos elementos discricionariedade, conceito jurídico indeterminado e accountability enquanto categorias tipológicas consistiu na primeira compreensão obtida neste estudo. Em seguida, a explanação crítica de cada um desses elementos tornou possível se constatar como estes se relacionam e podem incidir na seara tributária. 
Alcançados tais objetivos específicos, a descrição analítica e crítica dos programas Fomentar, Produzir e Pró Goiás demonstrou não apenas a estrutura e a procedimentalização de cada um desses incentivos, como também as nuances mais sensíveis no tocante à estruturação administrativa e a concessão de poderes em tais benefícios.

Por fim, diante da concretização do método hipotético-dedutivo, realizando-se a incidência das estruturas tipológicas jus administrativas no âmbito de cada um dos programas em estudo, constatou-se a amplitude da discricionariedade do Pró Goiás se comparado ao Fomentar e ao Produzir, de modo que o controle e o accountability do mais recente incentivo fiscal goiano deve ser ainda mais criterioso e rigoroso.

De todo modo, as mudanças na estrutura administrativa do Pró Goiás relatadas nos capítulos anteriores não servem para, por si só, infirmar o desde já insucesso do programa, tampouco para desqualificar as decisões políticas que serão tomadas. Tal análise não pode ser feita de maneira apriorística, sob pena de enviesar-se a pesquisa, diante da necessidade de ponderações casuísticas.

No entanto, o fato é que a alteração destacada é de considerável monta, de modo que, diante da escolha feita pelo legislador goiano, a qual se deve toda a deferência, se deve exercer rigoroso controle na concessão de tais incentivos, sob a perspectiva dos atuais debates jus administrativistas, em especial a necessidade de accountability no exercício de poderes discricionários e na complementação de conceitos jurídicos indeterminados.

\section{REFERÊNCIAS}

ÁVILA, Humberto. Competências tributárias - um ensaio sobre a sua compatibilidade com as noções de tipo e conceito. São Paulo: Malheiros, 2018.

ALMEIDA, Carlos Otávio Ferreira de/BEVILACQUA, Lucas. O planejamento financeiro responsável: Boa Governança e desenvolvimento nos 30 anos da Constituição Federal. In: BUISSA, Leonardo; REIMANN, Simon e MARTINS, Rafael (orgs.). Direito e finanças públicas nos 30 anos da Constituição: experiências e desafios nos campos do direito tributário e Financeiro. Florianópolis: Tirant Blanch, 2018, p. 29-53.

BERCOVICI, Gilberto. Constituição e superação das desigualdades regionais. In: GRAU, Eros e GUERRA FILHO, Willis Santiago (orgs). Direito Constitucional: estudos em homenagem a Paulo Bonavides. $1^{\text {a }}$ ed., $2^{\text {a }}$ Tiragem. São Paulo: Malheiros, 2003, p. 74-107.

BERCOVICI, Gilberto. Planejamento e políticas públicas: por uma nova compreensão do papel do Estado. In BUCCI, Maria Paula Dallari (org). Políticas Públicas: reflexões sobre o conceito jurídico. São Paulo: Saraiva, 2006, p. 143161.

BEVILACQUA, Lucas. Incentivos fiscais de ICMS e desenvolvimento regional. São Paulo: Quartier Latin, 2013.

BRASIL. Constituição Federal, de 05 de outubro de 1988. Diário Oficial da República Federativa do Brasil, 05 out. 1988.

BRASIL. Lei Federal n. 7.713, de 22 de dezembro de 1998. Diário Oficial da República Federativa do Brasil, 23 dez. 1998.

BRASIL. Lei Complementar n. 160, de 7 de agosto de 2017. Diário Oficial da República Federativa do Brasil, 08 ago. 2017.

CHEVALLIER, Jacques. O Estado Pós-Moderno. Trad. Marçal Justen Filho. Belo Horizonte: Fórum, 2009 (p.59-98). 
CONTI, José Maurício. Considerações sobre o Federalismo Fiscal brasileiro em uma perspectiva comparada. In: CONTI, José Maurício; SCAFF, Fernando Facury; BRAGA, Carlos Eduardo Faraco (Org.). Federalismo fiscal: questões contemporâneas. Florianópolis: Conceito Editorial, 2010, p. 15-34.

CONTI, José Maurício. Planejamento e Responsabilidade Fiscal. In: SCAFF, Fernando Facury e CONTI, José Maurício (orgs.). Lei de Responsabilidade Fiscal - 10 anos de Vigência - Questões Atuais. Florianópolis: Conceito Editorial, 2010, p. 39-56.

CORREIA NETO, Celso de Barros. Tributação e Direitos Fundamentais. In: CAMPOS, Carlos Alexandre de Azevedo; OLIVEIRA, Gustavo da Gama Vital de; MACEDO, Marco Antonio Ferreira (coord.). Direitos Fundamentais e Estado Fiscal - estudos em homenagem ao professor Ricardo Lobo Torres. Salvador: Jus Podivm, 2019.

DI PIETRO, Maria Sylvia Zanella. Da constitucionalização do direito administrativo: reflexos sobre o princípio da legalidade e a discricionariedade administrativa. Atualidades Jurídicas - Revista do Conselho Federal da Ordem dos Advogados do Brasil, Belo Horizonte, ano 2, n. 2, p. 83-106, jan./jun. 2012.

DI PIETRO, Maria Sylvia Zanella. Direito Administrativo. 29. Ed. Rev. Atual. e ampl. - Rio de Janeiro: Forense, 2016.

FARIA, Luís Alberto Gurgel de. A extrafiscalidade e a concretização do princípio da redução das desigualdades regionais. São Paulo: Quartier Latin, 2010, p. 154-187.

FURTADO, Celso. Formação Econômica do Brasil. 34 ed. São Paulo, Companhia das Letras, 2016.

GOIÁS. IMB - Instituto Mauro Borges. Análise do Censo Fomentar e Produzir. Estudos do IMB. Goiânia, 2014.

GOIÁS. IMB - Instituto Mauro Borges. Cenário Socioeconômico e Ambiental. Estudos do IMB. Goiânia, 2015.

GOIÁS. IMB - Instituto Mauro Borges. Incentivos Fiscais e o Estado de Goiás: Uma Análise de Impacto e do Custo Econômico dos Programas Fomentar/Produzir e Crédito Outorgado. Goiânia, 2019.

GOIÁS. IMB - Instituto Mauro Borges. Programa Fomentar/Produzir Informações e

Análises para o Estado e Microrregiões de Goiás. Estudos do IMB. Goiânia, 2012.

GOIÁS. Lei n. 9.489, de 19 de julho de 1984. Diário Oficial do Estado de Goiás, 31 jul. 1984.

GOIÁS. Lei n. 11.1380, de 19 de abril de 1990. Diário Oficial do Estado de Goiás, 20 abr. 1990.

GOIÁS. Lei n. 13.591, de 18 de janeiro de 2000. Diário Oficial do Estado de Goiás, 20 jan. 2000.

GOIÁS, Lei n. 14.469, de 16 de julho de 2003. Diário Oficial do Estado de Goiás, 21 jul. 20003.

GOIÁS. Lei n. 20.787, de 03 de junho de 2020. Diário Oficial do Estado de Goiás, 05 jun. 2020.

HOLMES, Stephen e SUSTEIN, Cass S. The cost of rights. Why liberty depends on taxes. New York/London: WW Norton \&amp; Company, 1999

MACHADO, Hugo de Brito. Teoria Geral do Direito Tributário. São Paulo: Malheiros, 2015.

MACHADO, Sophia Goreti Rocha; MOREIRA, André Mendes. Afinal, o que é tributo? In: CAMPOS, Carlos Alexandre de Azevedo; OLIVEIRA, Gustavo da Gama Vital de; MACEDO, Marco Antonio Ferreira (coord.). Direitos Fundamentais e Estado Fiscal - estudos em homenagem ao professor Ricardo Lobo Torres. Salvador: Jus Podivm, 2019.

MARQUES NETO, Floriano de Azevedo. Os grandes desafios do controle da Administração Pública. Fórum de Contratação e Gestão de Pessoas. Belo Horizonte, ano 9, n. 100, abril de 2010.

MARQUES NETO, Floriano de Azevedo; PALMA, Juliana Benacorsi de. Os sete impasses do controle da Administração Pública no Brasil. In: PEREZ, Marcos Augusto; SOUZA, Rodrigo Pagani de. Controle da Administração Pública. Belo Horizonte: Fórum, 2017, p. 21-38.

MATO GROSSO. Lei Complementar n. 93, de 5 de novembro de 2001. Diário Oficial do Estado do Mato Grosso, 5 nov. 2001.

MATO GROSSO. Lei n. 4.049, de 30 de junho de 2011. Diário Oficial do Estado do Mato Grosso, 1 jul. 2011.

MOREIRA, André Mendes; MACHADO, Sophia Goreti Rocha. Afinal, o que é Tributo? In: CAMPOS, Carlos Alexandre de Azevedo; OLIVEIRA, Gustavo da Gama Vital de; MACEDO, Marco Antonio Ferreira (coord.). Direitos Fundamentais e Estado Fiscal - estudos em homenagem ao professor Ricardo Lobo Torres. Salvador: Jus Podivm, 2019. 
MOREIRA NETO, Diogo de Figueiredo. Controle de contas e o equilíbrio entre os poderes: notas sobre a autonomia do sistema de controle externo. Revista Interesse Público, ano 19, n. 101, p. 15-53, jan/fev. 2017.

MOREIRA NETO, Diogo de Figueiredo. Mutações do Direito Administrativo, $3^{\mathrm{a}}$ ed. Rio de Janeiro: Renovar, 2007.

MOREIRA NETO, Diogo de Figueiredo. O Novo Papel do Estado na Economia. Revista de Direito Público da Economia - RDPE. Belo Horizonte, n. 11, ano 3 Julho / Setembro 2005

NASCIMENTO, Arthur Ramos do; RIBCZUK, Paula. Governança, governabilidade, accountability e gestão pública: critérios de conceituação e aferição de requisitos de legitimidade. Revista Direito Mackenzie, São Paulo, v. 9, n. 2, p. 218-237, 2015.

NÓBREGA, MARCOS. Orçamento, eficiência e performance budget. In: CONTI,José Maurício e SCAFF, Fernando Facury (coords). Orçamentos Públicos e direito financeiro. São Paulo: Editora Revista dos Tribunais, 2011, p. 693728.

PIVA, Sílvia Helena Gomes. Incentivos fiscais: uma visão normativa. Salvador: Editora JusPodivm, 2018.

REI, José Anijar Fragoso. Benefícios fiscais de ICMS para a efetivação de direitos fundamentais. 2017.

SAMPAIO, Luis Felipe. Gestão pública democrática e suas relações com supremacia do interesse público, discricionariedade administrativa e transparência. Revista de Direito Administrativo Contemporâneo, ReDAC vol.19, julho/gosto 2015.

SCAFF, Fernando Facury. O orçamento mínimo social garante a execução de políticas públicas. In: Crônicas de Direito Financeiro - Tributação, Guerra Fiscal e Políticas Públicas. São Paulo: CONJUR Editorial, 2016, p. 225-228.

SIU, Marx Chi Kong. Accountability no Setor Público: uma reflexão sobre transparência governamental no combate à corrupção. Revista do TCU, Brasília, ano 43, número 122, setembro/dezembro 2011.

SUNDFELD, Carlos Ari. Direito Administrativo para Céticos. São Paulo: Malheiros, 2012.

TORRES, Heleno Taveira. Constituição financeira e o federalismo financeiro cooperativo equilibrado brasileiro. Revista Fórum de Direito Financeiro e Econômico n. 5, mar./ago.2014, p.25-54.

VALLE, Vanice Regina Lírio do. Réquiem para ação administrativa planejada: a rutura entre as dimensões executiva e orçamentária. In: BUISSA, Leonardo; REIMANN, Simon e MARTINS, Rafael (orgs.). Direito e finanças públicas nos 30 anos da Constituição: experiências e desafios nos campos do direito tributário e financeiro. Florianópolis: Tirant Blanch, 2018, p. 319-340.

Recebido/Received: 25.06.2020.

Aprovado/Approved: 28.09.2020. 